\title{
Bradycardia in elderly patients: look at the body temperature
}

\author{
Alfonso Sforza, ${ }^{1}$ Maria Viviana Carlino, ${ }^{1}$ Costantino Mancusi, ${ }^{2}$ Emanuela Catapano, ${ }^{1}$ Graziella Castellano, ${ }^{1}$ \\ Anita Costanzo, ${ }^{1}$ Vittorio Luiso, ${ }^{1}$ Arturo Izzo, ${ }^{1}$ Mario Guarino ${ }^{1}$ \\ ${ }^{1}$ Emergency Department, C.T.O. Hospital, Naples; ${ }^{2}$ Hypertension Research Center, UOC Emergency Medicine, Federico II \\ University Hospital, Naples, Italy
}

\begin{abstract}
We describe a case of an 83-year-old man who presented to the Emergency Department for bradycardia and reduced level of consciousness. His conditions had progressively worsened in the last few days and bradycardia induced his relatives to call on emergency team. He presented with hypoxia, cough, bradycardia, and a reduced Glasgow Coma Scale value. The body temperature was not detected by standard thermometer and the electrocardiogram showed sinus bradycardia with prominent Osborne wave in the lateral precordial leads. His rectal temperature was $30.1^{\circ} \mathrm{C}$ and the diagnostic work up showed a right lung pneumonia. He underwent active and passive rewarming treatment and sepsis treatment. Electrocardiographic abnormalities disappeared after rewarming and the patient was admitted to sub-intensive care unit.
\end{abstract}

\section{Introduction}

The diagnosis of hypothermia may be relatively easy in patients found outdoors in cold temperature conditions but may be also overlooked in patients found indoors especially in elderly patients presenting with vague complaints of mental and/or motor skill deterioration and in patients with many co-morbidities. Bradycardia may be the only alarm bell that induces family members and/or the family doctor to request activation of the emergency team.

Correspondence: Alfonso Sforza, Emergency Department, C.T.O. Hospital, Azienda Ospedaliera dei Colli, viale Colli Aminei 21, 80141 Naples, Italy.

Tel.: +39.0817068735.

E-mail: alfosfo@hotmail.it

Key words: Indoor hypothermia; Osborne wave; rewarming therapy; emergency department.

Contributions: AS and MVC conceived the paper and wrote the manuscript; $\mathrm{CM}, \mathrm{EC}, \mathrm{GC}, \mathrm{AC}, \mathrm{VL}, \mathrm{AI}$ and $\mathrm{MG}$ contributed to the discussion and edited the manuscript; EC was the nurse dedicated to patient care.

Received for publication: 12 May 2019.

Revision received: 12 July 2019.

Accepted for publication: 19 August 2019.

This work is licensed under a Creative Commons Attribution NonCommercial 4.0 License (CC BY-NC 4.0).

${ }^{\circ}$ Copyright: the Author(s), 2019

Licensee PAGEPress, Italy

Italian Journal of Medicine 2019; 13:241-243

doi:10.4081/itjm.2019.1181

\section{Case Report}

An 83-year-old man was conducted to the emergency department for bradycardia and progressive reduction of the level of consciousness with aphasia. He had history of dementia and arterial hypertension on treatment with psychoactive and antihypertensive drugs. His blood pressure was 110/70 $\mathrm{mmHg}$, heart rate was 40 beats/minute, oxygen saturation was $86 \%$ in room air, respiratory rate was 16 breaths per minute and he had cough. Clinical examination revealed crackles in the right lung, mild peripheral edema, no abdominal pain, decreased wakefulness and aphasia (Glasgow Coma Scale $=9$ ). The electrocardiogram shows slow regular sinus rhythm with ventricular extra-systolic beats configuring a pattern of bigeminy, tremor artefacts from shivering on the baseline, first degree atrioventricular block, QT dispersion and normal electric axis. Leads V4-V5-V6 show prominent Osborne wave also appreciable in the inferior leads (Figure 1). The axillary temperature with standard thermometer could not be determined. Patient's core body temperature (rectal temperature) was $30.1^{\circ} \mathrm{C}$, blood gas analysis showed a mixed disorder (metabolic acidosis with respiratory alkalosis, Table 1), a moderate hypoxemia with normal electrolytes, glucose and hemoglobin levels, laboratory tests showed a non-specific picture with augmented C-reactive protein (Table 2). Chest X-ray revealed a right lung pneumonia while head computed tomographic scan showed chronic cerebral vasculopathy and cortical and subcortical atrophy. After obtaining a central venous line in the right internal jugular vein, the patient underwent fluid resuscitation with warmed Ringer solution, he received broad-spectrum antibiotic therapy, and warmed and humidified oxygen via high-flow 
nasal cannula. He received active external rewarming via forced-air warming system. After rewarming heart rate improved and Osborne wave disappeared (Figures 2 and 3), and after reaching the temperature of $36^{\circ} \mathrm{C}$ he was admitted to sub-intensive care unit.

\section{Discussion}

The diagnosis of indoor hypothermia is not obvious in the emergency department especially because it often affects elderly patients with dementia and reduced mobility who generally present with vague symptoms like mental and motor skills deterioration. ${ }^{1}$ Moreover, standard clinical thermometers are not able to record the lowest body temperatures for which lowreading thermometers are required. ${ }^{2}$ The electrocardiographic characteristics of hypothermia depend on the value of core body temperature. As body temperature falls further, all metabolic and cardiovascular processes slow progressively. Heart rate and conduction velocity decline, resulting in bradycardia and prolongation of the PR, QRS, and QT intervals. Artefacts due to shivering are common in the earliest phases but the ability to shiver diminishes as body temperature falls. Atrial fibrillation with slow ventricular rate and/or heart block may appear. J wave (Osborne wave) generally appears during moderate hypothermia $\left(32.2^{\circ} \mathrm{C} / 90^{\circ} \mathrm{F}-28^{\circ} \mathrm{C} / 82.4^{\circ} \mathrm{F}\right)$ while ventricular dysrhythmias and/or asystole may occur during severe hypothermia $\left(<28^{\circ} \mathrm{C} / 82.4^{\circ} \mathrm{F}\right) .^{1-3}$ Ventricular tachycardia or fibrillation may also occur during rewarming. Osborne wave is a hump-shaped elevation of the terminal portion of the QRS whose magnitude correlates with the severity of hypothermia. It is typically observed in the inferior and lateral precordial leads and generally disappears after rewarming although it can persist 12

Table 1. Blood gas analysis in room air.

\begin{tabular}{lcc}
\hline Parameter & Value & Unit of measure \\
\hline $\mathrm{pH}$ & 7.38 & - \\
\hline $\mathrm{pCO}_{2}$ & 32 & $\mathrm{mmHg}$ \\
\hline $\mathrm{pO}_{2}$ & 49 & $\mathrm{mmHg}$ \\
\hline $\mathrm{Na}^{+}$ & 133 & $\mathrm{mmol} / \mathrm{L}$ \\
\hline $\mathrm{K}^{+}$ & 4.0 & $\mathrm{mmol} / \mathrm{L}$ \\
\hline $\mathrm{Ca}^{++}$ & 1.28 & $\mathrm{mmol} / \mathrm{L}$ \\
\hline $\mathrm{Glu}^{+}$ & 128 & $\mathrm{mg} / \mathrm{dL}$ \\
\hline $\mathrm{Lat}^{-}$ & 1.8 & $\mathrm{mmol} / \mathrm{L}$ \\
\hline $\mathrm{HCO}_{3}^{-}$ & 18.9 & $\mathrm{mmol} / \mathrm{L}$ \\
\hline $\mathrm{SO}_{2}$ & 86.2 & $\%$ \\
\hline $\mathrm{Hb}^{-}$ & 12.6 & $\mathrm{~g} / \mathrm{dL}$
\end{tabular}

to $24 \mathrm{~h}$ after restoration of body temperature. It is caused by a transmural voltage gradient created by the presence of a prominent action potential notch in the epicardium but not in the endocardium generated by more prominent transient outward potassium current in epicardial compared to endocardial layers. ${ }^{4}$ The Osborne wave is considered by many to be pathognomonic for hypothermia, but it may also occasionally be seen in hypercalcemia ${ }^{1}$ and in central nervous system disorders, including massive head injury and sub-

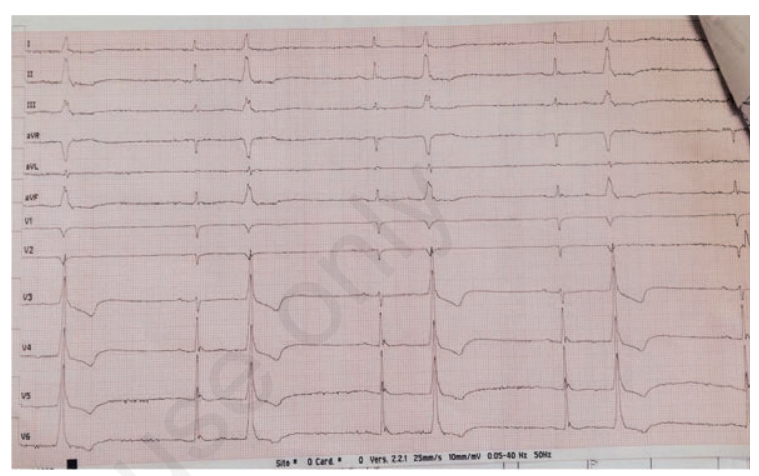

Figure 1. Electrocardiogram on presentation.

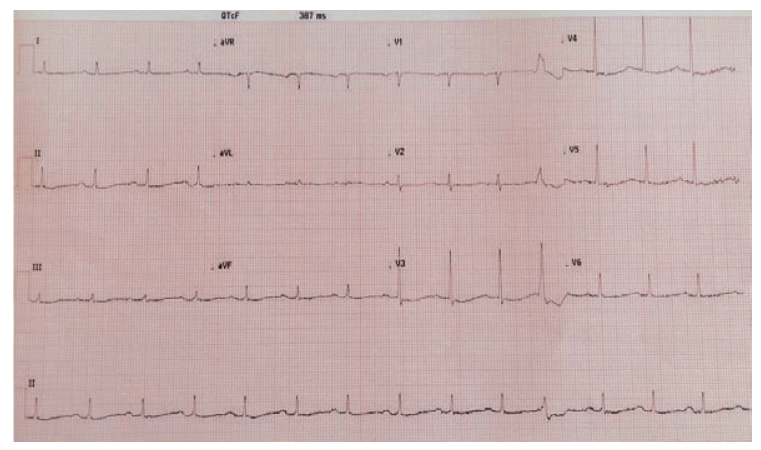

Figure 2. Electrocardiogram after rewarming.

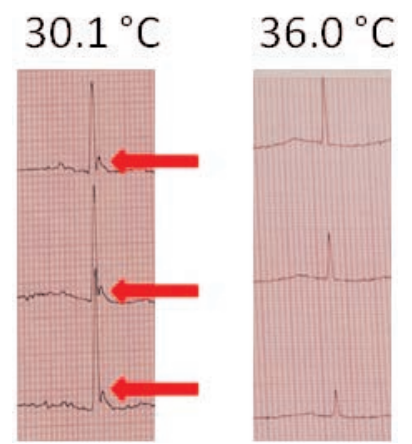

Figure 3. Osborne wave in lead V4, V5 and V6 (red arrows) disappears after rewarming therapy. 
Table 2. Laboratory tests.

\begin{tabular}{lcc}
\hline Parameter & Value & Unit of measure \\
\hline Red blood cells & 4.00 & $\mathrm{x} 10^{6} / \mathrm{mL}$ \\
\hline Hemoglobin & 13.1 & $\mathrm{~g} / \mathrm{dL}$ \\
\hline Hematocrit & 38.0 & $\mathrm{x} 10^{3} / \mathrm{mL}$ \\
\hline Platelets & 125 & $\mathrm{x} 10^{3} / \mathrm{mL}$ \\
\hline White blood cells & 4.99 & $\mathrm{x} 10^{3} / \mathrm{mL}$ \\
\hline Neutrophils & 4.51 & $\mathrm{mg} / \mathrm{dL}$ \\
\hline Glucose & 123 & $\mathrm{mg} / \mathrm{dL}$ \\
\hline Urea & 75 & $\mathrm{mg} / \mathrm{dL}$ \\
\hline Creatinine & 1.47 & $\mathrm{mEq} / \mathrm{L}$ \\
\hline Sodium & 136 & $\mathrm{mEq} / \mathrm{L}$ \\
\hline Potassium & 4.1 & $\mathrm{U} / \mathrm{L}$ \\
\hline Lactate dehydrogenase & 161 & $\mathrm{UL} / \mathrm{L}$ \\
\hline Aspartate aminotransferase & 25 & $\mathrm{UL} / \mathrm{L}$ \\
\hline Alanine aminotransferase & 16 & $\mathrm{mg} / \mathrm{dL}$ \\
\hline Bilirubin & 0.78 & - \\
\hline Prothrombin time-international normalized ratio & 0.93 & $\mathrm{mg} / \mathrm{L}$ \\
\hline Activated partial thromboplastin time-ratio & 1.21 & \\
\hline C-reactive protein & 60.27 & \\
\hline
\end{tabular}

arachnoid hemorrhage. The $\mathrm{J}$ wave may even be a drug effect or, rarely, a normal variant. ${ }^{3}$ The most important treatment for hypothermia-induced arrhythmias is the rewarming. Patient should be covered and conducted in a warm room to prevent further loss of heat. Patient can receive active external rewarming treatment with the application of heat directly to the skin via forced-air warming systems or warming blanket. Active core rewarming includes the administration of warmed and humidified oxygen, heated intravenous fluids and warm lavage of several body cavities. In the most serious cases extracorporeal blood warming should be used in intensive care unit. ${ }^{2}$

\section{Conclusions}

Bradycardia and Osborne wave should make us think of the presence of hypothermia in patients presenting with confusion and/or decreased level of consciousness and/or limitations of motor skills especially in the elderly population and during cold seasons. Core body temperature must be measured with special low-reading thermometers as soon as possible when hypothermia is suspected. Active rewarming may be achieved via administration of warmed oxygen and fluids and application of heat directly to the skin via forced-air warming systems or warming blanket in the emergency department.

\section{References}

1. Van Mieghem C, Sabbe M, Knockaert D. The clinical value of the ECG in noncardiac conditions. Chest 2004; 125:1561-76.

2. McCullough L, Arora S. Diagnosis and treatment of hypothermia. Am Fam Physician 2004;70:2325-32.

3. Slovis C, Jenkins R. ABC of clinical electrocardiography: conditions not primarily affecting the heart. BMJ 2002;324:1320-3.

4. Yan GX, Antzelevitch C. Cellular basis for the electrocardiographic J wave. Circulation 1996;93:372-9. 